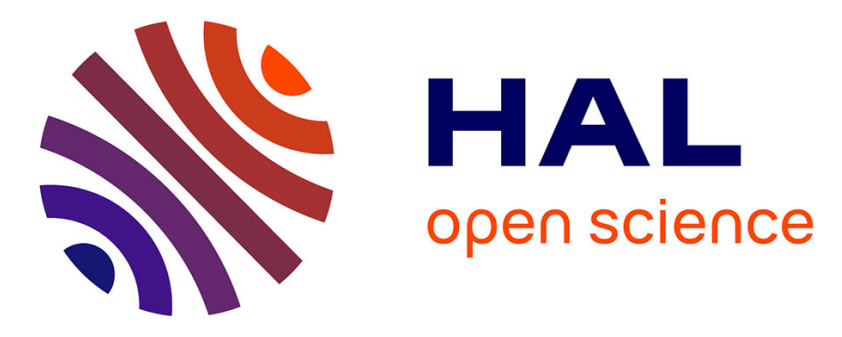

\title{
Liaison acquisition: debates, critical issues, future research
}

\author{
Jean-Pierre Chevrot, Céline Dugua, Mylène Harnois-Delpiano, Anne Siccardi, \\ Elsa Spinelli
}

\section{- To cite this version:}

Jean-Pierre Chevrot, Céline Dugua, Mylène Harnois-Delpiano, Anne Siccardi, Elsa Spinelli. Liaison acquisition: debates, critical issues, future research. Language Sciences, 2013, 39, pp.83-94. 10.1016/j.langsci.2013.02.011 . hal-00850511

\section{HAL Id: hal-00850511 https://hal.science/hal-00850511}

Submitted on 7 Aug 2013

HAL is a multi-disciplinary open access archive for the deposit and dissemination of scientific research documents, whether they are published or not. The documents may come from teaching and research institutions in France or abroad, or from public or private research centers.
L'archive ouverte pluridisciplinaire HAL, est destinée au dépôt et à la diffusion de documents scientifiques de niveau recherche, publiés ou non, émanant des établissements d'enseignement et de recherche français ou étrangers, des laboratoires publics ou privés. 


\title{
Liaison acquisition: debates, critical issues, future research Jean-Pierre CHEVROT ${ }^{\mathrm{a}, \mathrm{b}}$, Céline DUGUA ${ }^{\mathrm{c}}$, Mylène HARNOIS-DELPIANO ${ }^{\mathrm{a}}$, Anne SICCARDI ${ }^{\text {a }}$, Elsa SPINELLI ${ }^{\text {b,d }}$
}

${ }^{a}$ LIDILEM - Laboratoire de Linguistique et Didactique des Langues Étrangères et Maternelles, Université de Grenoble 3, BP 25, 38040 Grenoble Cedex 9, France.

${ }^{\mathrm{b}}$ Institut Universitaire de France.

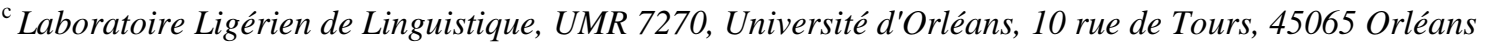
Cedex02, France.

${ }^{\mathrm{d}}$ LPNC-Laboratoire de Psychologie et Neurocognition, UMR 5105, Université de Grenoble 2, BP 47, 38040 Grenoble Cedex 9, France.

\section{e-mail address of each author}

Jean-Pierre Chevrot : jpchevrot@wanadoo.fr_Anne Siccardi : anne.siccardi@gmail.com Celine Dugua : celine.dugua@univ-orleans.fr Elsa Spinelli : elsa.spinelli@upmf-grenoble.fr Mylène Harnois-Delpiano : myleneharnois@yahoo.fr

Corresponding author: Jean-Pierre Chevrot, LIDILEM, BP 25, 38040 Grenoble cedex 9, France. e-mail: jpchevrot@wanadoo.fr. Tel. : +33 (0) 4764190 46, Fax : +33 (0) 4768243 95

\begin{abstract}
Liaison is a sandhi phenomenon in French. Over the last four decades, it has given rise to many different models illustrating the whole range of phonological theories. More recently, new studies have documented its acquisition in French-speaking children as well as adult learners of French as a second language. These studies have resulted in the elaboration of two models of the acquisition process: 1/ the constructionist model (Chevrot, Dugua \& Fayol, 2009; Nicoladis \& Paradis, 2011) developed within the framework of the usage-based theories; $2 /$ the phonological model (Wauquier, 2009) which represents the framework of nonlinear phonology. Our aim is to re-examine the usage-based model in the light of the criticisms and suggestions made by Wauquier (2009). We shall first present the two models and then examine the issues under discussion. After that, we shall present longitudinal data testing a prediction made by the phonological model with regard to the generalization process in L1 and L2 acquisition. To conclude, we shall identify the points that remain to be clarified for each of the models and the directions which future research should take.
\end{abstract}

Key words

liaison acquisition; modeling; construction grammar; non linear phonology; floating autosegment; item-based schema 


\section{Introduction}

In French, liaison takes the form of an alternation that can be observed at word boundaries. For four decades, phonological theories have been using it as an empirical testing ground. There have therefore been many attempts to develop linguistic models of liaison elaborated within a variety of theoretical frameworks (for an overview, see Côté, 2011). More recently, new research has endowed liaison with the status of an interdisciplinary object at the interface between linguistics and psycholinguistics. On the one hand, studies of adult subjects have explored the cognitive processes involved in lexical access to liaised words (for a review, see Wauquier, 2009). On the other, works conducted among native French-speaking children and adult learners of French as a second language have documented and modeled its acquisition. It is the debates concerning the acquisition of liaisons that form the object of the present paper.

Our starting point is the constructionist model of liaison acquisition in French-speaking children proposed by Chevrot et al. (2009) ${ }^{1}$ within the framework of usage-based theories (Tomasello, 2003). This model is based on studies conducted among children in the form of both corpus analyses (Chabanal, 2003; Chevrot et al., 2007) and experiments (Chevrot et al., 2005; Dugua, 2006; Nardy, 2008; Chevrot et al., 2009; Dugua et al., 2009; Gallot et al., 2009; Chevrot et al., 2011). It has been reformulated by Nicoladis \& Paradis (2011) within an identical theoretical framework. In an article published in 2009, Wauquier drew on an exhaustive review of recent data to question the validity of this model. In this article, she set out in detail a number of criticisms that had their origins in earlier publications (WauquierGravelines \& Braud, 2005; Wauquier et al., 2005) and proposed an alternative model based on the framework of nonlinear phonology.

Our aim here is to examine the usage-based model (Chevrot et al., 2009) in the light of Wauquier's criticisms and propositions (2009). After presenting the functioning of liaison in adults, we shall set out the two models and the issues characterizing the debate. We shall then present the longitudinal data relating to the process involved in the generalization of liaisons in children and adult learners. To conclude, we shall indicate the areas of the two models which still remain to be clarified and point out valuable avenues for future research.

\footnotetext{
${ }^{1}$ This article is dedicated to Jacques Durand. Through his single-mindedness and enthusiasm, Jacques initiated and developed the database Phonologie du Français Contemporain (http://www.projet-pfc.net/) which has given the study of liaisons the empirical basis that such a complex phenomenon demands. The PHONLEX project (ANR BLAN07-2-187755) which he designed and coordinated, and more generally his work on variation, have provided a decisive stimulus to research presented in this article.
} 


\section{Liaison in adults}

In French-speaking adults, liaison consonants appear between two words (word1 and word2) in connected speech. For this consonant to appear, word2 must start with a vowel when spoken in isolation. For instance, the French determiner un 'a/one' (word1) is not followed by a liaison when used at the end of an utterance (J'en choisis un [3 $\left.\tilde{a} \int w a z i \tilde{e}\right]$ 'I

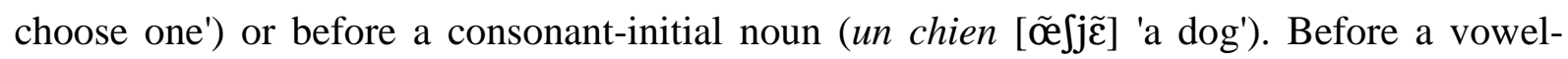
initial noun, the liaison consonant /n/ appears between un and the following word (un arbre 'a

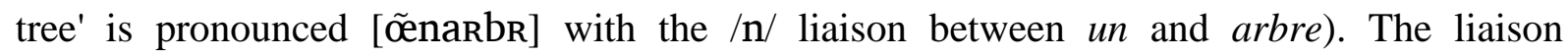
consonant generally forms a syllable with the initial vowel of the word2 (e.g. un arbre is syllabified [थ̃.narbr]). Both the possibility of producing a liaison and its phonetic content (/n/, /z/ and /t/ in $99.7 \%$ of cases, Boë \& Tubach, 1992) depend on the word1. For example, the word1s un 'a/one' or aucun 'none' both trigger an /n/ liaison, the word1s petit or grand a /t/ liaison, the word1s gros or deux a /z/ liaison, whereas joli or beau do not trigger any liaison.

Liaisons are frequent in French adult speech as they occur approximately every 16 words (Boë \& Tubach, 1992). The contexts of appearance of liaison are usually divided into two categories: the contexts where the liaison is categorical and the contexts where it is variable. Based on observations of the speech of 100 French speakers, Durand \& Lyche (2008) found that liaison appears to be categorical only after preverbal clitics (/z/ liaison in ils arrivent [ilzaniv] 'they come/are coming'), after determiners (/n/ liaison in un arbre [ø̃narbR] 'a/one tree'), in verb + clitic inversions (/t/ liaison in Comment dit-on? [komãditว̃] 'how do we say?') and in certain frozen expressions (/t/ liaison in tout-à-fait [tutafe] 'quite'). Other liaison contexts appear to be variable. For example, between an adjective and a noun, a liaison may or may not be produced: gros éléphant 'big elephant' is pronounced either [grozelefã] with a /z/ liaison or [gRoelefã] without any liaison. The variable liaisons are known to function as sociolinguistic markers. Their realization also depends on the geographical origin of the speaker (Durand \& Lyche, 2008). 


\section{Two concepts of first-language liaison acquisition}

The psycholinguistic framework within which work on liaison acquisition has been conducted has been influenced by the debates concerning its phonological modeling in adults. The models of acquisition in question differ in terms of the mechanism they propose to account for the alternation between productions with and without liaisons. Referring to the proposals advanced by Bybee (2001), both Chevrot et al. (2009) and Nicoladis \& Paradis (2011) account for this alternation in terms of competition between constructions. Wauquier (2009) invokes the proposals made by Encrevé (1988) who explained alternation in terms of a phonological mechanism at work within the framework of multilinear representations. To reflect this crucial difference, we shall refer in the following to the constructionist model and the phonological model. To answer the question raised by Wauquier (2009) who was unsure of the empirical scope of the constructionist model, we can state that it relates only to determiner-noun liaisons and that the empirical material underpinning it consists primarily of this type of liaison (see, however, Nardy et al., to appear, for an attempt to extend the model to variable liaisons between adjective and noun).

\subsection{The constructionist model of liaison acquisition}

Bybee's (2001) ideas concerning liaison are situated in a more general framework in which words, inflected forms and frequent word sequences are memorized in the lexicon and linked together by constructions which encode conventionalized patterns of relations between form, meaning and function (Goldberg, 2003). The different types of constructions are situated on a continuum involving two dimensions: from the concrete to the abstract and from the simple to the complex (Croft \& Cruse, 2004). Construction may therefore take the form of a word (simple and concrete), a sentence structure formed from abstract categories (complex and abstract), a frozen expression or chunk (complex and concrete) or a mixed configuration which combines phonologically specified elements with open slots and abstract categories, as in the case of the schemas accounting for the production of liaison. Certain liaisons are memorized as phonological elements in stored chunks. Connecting these chunks on the basis of their phonological, semantic and functional similarities results in more abstract productive schemas, which allow the speaker to generate liaisons which he has never heard.

In line with Bybee's ideas, the constructionist model of liaison acquisition assumes that early on, children memorize concrete chunks of speech, some of which contain determiner + noun sequences that may or not include a liaison. This assumption is based on works showing that young children (Bannard \& Matthews, 2008; Pine \& Lieven, 1993, 1997) and adults 
(Arnon, \& Snider, 2010; Janssen \& Barber, 2012) store sequences consisting of several words. Children then have to segment these sequences in order to extract the units which can be used in other utterances (Peters, 1985; Tomasello, 2003).

The segmentation process represents an early exploitation of the probable correspondence between the start of a word and syllable onset (Goyet et al., 2010; Mattys \& Jusczyk, 2001). Furthermore, the French language contains approximately three times more words that start with a consonant than with a vowel (Chevrot et al., 2009). When confronted with determinernoun sequences, French-speaking children would thus place a lexical boundary before the consonant following the determiner. In the case of consonant-initial nouns (as in the sequence les filles, [lefij] 'the girls'), the resulting word form is similar to the adult form (i.e. /fij/). If the chunk includes a liaison forming a syllable with the following vowel (e.g. /z/ liaison in les arbres [lezarbR] 'the trees'), children place a lexical boundary in front of the liaison. As a result, the liaison consonant is attached to the start of the lexical representation of the noun ([lezarbR] is segmented [le.zanbR] with the word form /zaRbR/ for arbre). If children apply this syllabic strategy in each liaison context where the same noun appears (after a $/ \mathrm{n} /$ liaison

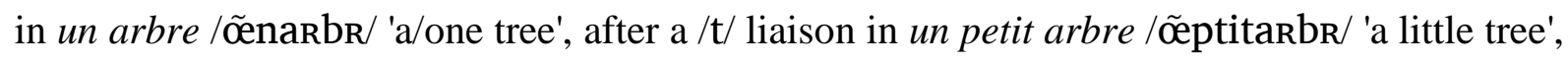
etc.), they obtain multiple variants of each noun: /narbR/, /zarbr/, /taRbR/. These consonantinitial variants may be joined by the vowel-initial variant (/aRbR/) of certain nouns which are heard in isolation or after an adjective which does not trigger a liaison (e.g. joli arbre 'pretty tree').

The segmentation of the noun is correlative with the segmentation of the determiner, which belongs to a restricted class. The formation of a schema results from the establishment of relationships between memorized chunks which share phonological and semantic contents. We would therefore expect schemas to be elaborated on the basis of the determiners, which are present in a large number of chunks. The determiners therefore become a concrete element in a schema of the form les $+\mathrm{X}$ which results from the connection between chunks that contain les (les arbres, 'the trees', les livres 'the books', les filles 'the girls', etc.). These schemas provide a slot $\mathrm{X}$ in which children can insert segmented variants of the noun. They reveal children's ability to combine determiners and nouns to create new nominal phrases. 
During this first stage (2-4 years), children's liaison skills consist of three components: 1/ stored determiner-noun sequences; $2 /$ general schemas that do not contain any information about liaison (e.g. les $+\mathrm{X}, u n+\mathrm{X}$, etc.); 3/ alternating noun variants, some of which start with a liaison (e.g. /nakbR/, /zarbR/) and others with a vowel (e.g. /arbR/).

While achieving this first stage, children continue to memorize frequent determiner-noun sequences, some of which contain a liaison (e.g. les ours /lezurs/ 'the bears', les ânes /lezan/ 'the donkeys', les amis /lezami/ 'the friends'). By connecting these chunks, they generalize specific schemas of the type les $+/ \mathrm{zX} /$ that specify the nature of the lexical variant that should fill the slot following a specific determiner (i.e. les $+/ \mathrm{zX} /$ means: the determiner les should be followed by noun variants starting with /z/: /zarbR/ /zami/, /zan/, etc.). This schema makes it possible to produce correct liaisons without having to memorize all the combinations of determiners and noun variants.

During the second stage (4-5 years of age), children's liaison skills consist of four components: 1/ stored determiner-noun sequences; 2 / general schemas (les $+\mathrm{X}, u n+\mathrm{X}$, etc.); 3/ alternating noun variants starting with a liaison (e.g./naRbR/, /zaRbR/) or with a vowel (e.g. /aRbR/); 4/ specific schemas which generalize the relation between a determiner and a class of noun variants (e.g. les $+/ \mathrm{zX} /$, un $+/ \mathrm{nX} /$ ).

Only the two stages described above are underpinned by a substantial body of data.

\subsection{The phonological model of liaison acquisition}

The basis for the phonological model is quite different. Within the multilinear framework proposed by Encrevé (1988) following earlier propositions made by Clements \& Keyser (1983), multilinear representations of word forms consist of parallel autosegmental tiers which themselves contain sequences of units (the autosegments). Each tier contains autosegments that provide information about a particular phonological aspect: segment tier (which encodes the phonetic content of the phonemes), syllable tier (which encodes the components of the syllable: onset, rime, nucleus, coda), tone tier, etc. The lexical representations are realized through the association of each autosegment with an abstract position in a timing tier or skeleton of neutral positions which provides as many slots as there can be segments in a word. Conventions of correct formation that can be configured for each language define the conditions governing the association between autosegments and the positions in the skeleton, with any autosegment for which there is no association not being 
produced. Within this framework, the liaison is a final consonant of a word1 which is unanchored at two levels (double-floating autosegment). In effect, neither its segment content (/n/, /z/, etc.) nor its syllabic position (coda) are anchored in the lexical representation of the word1, thus differentiating it from other consonants. The liaison is therefore produced only if its segment content has a position at which it is anchored in the skeleton. Furthermore, two autosegments from the syllable tier can be anchored at the position in the skeleton that corresponds to a liaison: either the onset of the word2, in which case the liaison is linked ([za.ve.zõe.Rev] j'avais un rêve, 'I had a dream'); or the coda of the final syllable of the word1, in which case it is unlinked ([za.vez.õ..Rev]). The unlinked liaison is a specific variant of public speaking (Encrevé, 1988) that is rarely found in everyday speech (Durand et al., 2011).

Developed within this framework, the phonological model of liaison acquisition is subdivided into four stages (Table 1 for stages 1-3). In the same way as the constructionist model, it postulates a first stage in which nouns are stored in the lexicon preceded by a position, possibly consisting of a single vowel, coding the location of what will subsequently be the determiner. However, these stored global forms would already be accompanied by a representation establishing relations between the segmental aspects (the six segments spelling the sequence les amis (/lezami/ 'the friends') and the syllabic aspects (the internal hierarchy of the constituents of the syllable: onset, nucleus and rime). In this early representation, the associations between the segmental and syllabic autosegments and the positions in the skeleton would, by default, be strictly assigned: biunivocal association of each autosegment with the corresponding position in the skeleton and absence of branching syllabic structures (e.g. a complex onset such as /tr/ corresponds to two positions). This representation accounts for the prevalence of $\mathrm{CV}$ sequences in early speech. 


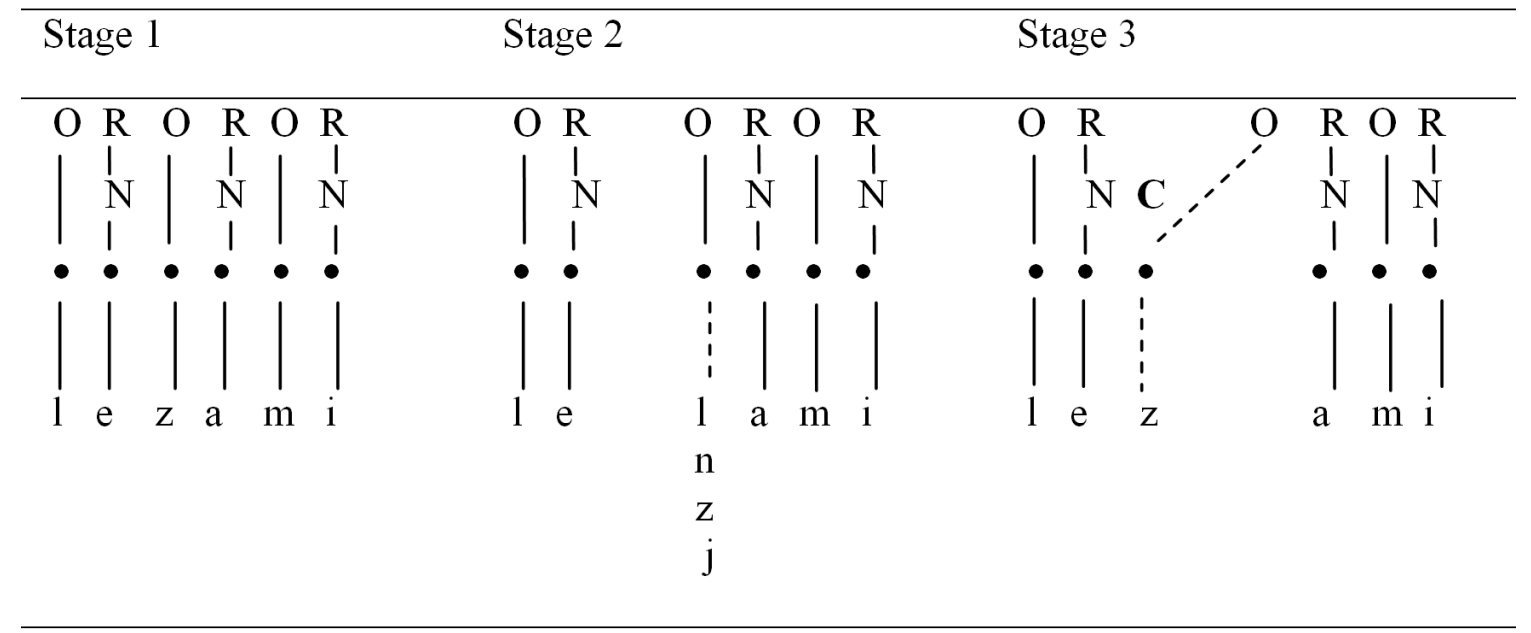

Table 1 - The first three stages of the phonological model of liaison acquisition (from Wauquier, 2009) (O: syllable onset; R: rime; N: nucleus; C: coda).

The second stage is characterized by the appearance of liaison errors at the time when children segment the determiner and noun and choose their form. These errors testify to the new ability to process syllabic and segmental information independently. The representations therefore move away from the strict alignment that is characteristic of the previous stage. In line with the Maximum Onset Principle, the position of the syllable onset continues to be associated with the start of the noun. Only the segmental content becomes a floating autosegment (dotted line in Table 1) even though, at this stage, it is not yet specified. Children therefore use a variety of ways to assign segmental content to this onset position, notably through statistical inferences drawn from the contexts in which the noun has been encountered. In particular, they would use the $/ 1 /, / n /$ and $/ \mathrm{z} /$ resulting from elision and liaison ([lelefã], [nelefã], [zelefã] for éléphant 'elephant'), /j/ ([jelefã]) as a default segment, a segment resulting from consonant harmony ([ㅌefefã $])$, or an idiosyncratic content ([pelefã]]).

The third stage is characterized by the disappearance of liaison errors due to a morphological bootstrapping phenomenon (Wauquier-Gravelines \& Braud, 2005). Children encode liaisons in the form of floating segments at the end of determiners and adjectives when they discover "that the determiner un [one/a] acquires a nasal consonant in the feminine and that adjectives such as petit, grand, gros [small/big/fat] acquire a consonant when inflected (petite, grande, grosse) or nominalized (petitesse, grandeur [smallness/size]" (our translation, p.62). The liaison then has the status of a double-floating autosegment (a segment that is unanchored in terms of both content and syllabic position) which characterizes it in adult representations (see the dotted lines in stage 3, Table 1). Its segmental content is specified but 
is not anchored at a position in the skeleton and may or may not be produced. The syllabic autosegment 'coda', which corresponds to the liaison, has no lexical association with a position in the skeleton. As a result, the null onset position postulated at the start of vowelinitial words (i.e. an onset with neither a position in the skeleton nor any segmental content, Encrevé, 1988: 155) may become anchored at the skeletal position corresponding to the liaison and form a syllable. According to Wauquier (2009), the "rules governing the morphophonological alternation of the determiner are mastered at this point." (our translation, p.121).

The fourth stage is characterized by the mastery of variable liaisons which takes place when the categorical liaison is generalized. Children discover that production and linkage are optional in certain contexts and that they are imbued with a socio-stylistic value. This stage is not thought to testify to any phonological acquisition but instead to be associated with pragmatic skills, the learning of writing and the norms of the school environment.

\section{The issues involved in the debate}

Wauquier (2009) emphasizes a major difference between the two models. Unlike the phonological scenario, the constructionist scenario does not treat the liaison as a phonological object. Table 2 summarizes the production mechanisms postulated by the constructionist model. It can be seen here that the production of a prenominal liaison, whether correct or incorrect, or the omission of this liaison results from the lexical selection of one or other of the variants of the noun. 


\begin{tabular}{|c|c|c|c|}
\hline Production & Mechanism & Example & Development with age \\
\hline $\begin{array}{l}\text { Replacement } \\
\text { error }\end{array}$ & $\begin{array}{l}\text { Insertion of a C-initial variant } \\
\text { in a general schema based on } \\
\text { a determiner that induces a } \\
\text { liaison }\end{array}$ & $\begin{array}{l}\text { Insertion of the variant /nami/ in } \\
\text { the schema les }+/ \mathrm{X} / \\
\text { Replacement of the /z/ expected } \\
\text { after les by /n/: [lenami] }\end{array}$ & $\begin{array}{l}\text { Decrease followed by } \\
\text { disappearance between } 2 \\
\text { and } 6 \text { years (Chevrot et } \\
\text { al., 2007, 2011; Dugua, } \\
\text { 2006). }\end{array}$ \\
\hline $\begin{array}{l}\text { Adjunction } \\
\text { error }\end{array}$ & $\begin{array}{l}\text { Insertion of a C-initial variant } \\
\text { in a context where there is no } \\
\text { liaison, for example a schema } \\
\text { based on a determiner that } \\
\text { does not induce any liaison }\end{array}$ & $\begin{array}{l}\text { Insertion of the variant /nami/ in } \\
\text { the schema } l e+/ \mathrm{X} / \text { 'the+singular' } \\
\text { Adjunction of } / \mathrm{n} / \text { outside of the } \\
\text { liaison context: [lənami] }\end{array}$ & $\begin{array}{l}\text { No study available on } \\
\text { development except at } \\
\text { start of utterance: [nuRs]! } \\
\text { ('Bear !' to call a bear): } \\
\text { decrease between } 2 \text { and } 6 \\
\text { years (Chevrot et al., } \\
\text { 2009) }\end{array}$ \\
\hline Omission error & $\begin{array}{l}\text { Insertion of a V-initial variant } \\
\text { in a general schema based on } \\
\text { a determiner that induces a } \\
\text { liaison }\end{array}$ & $\begin{array}{l}\text { Insertion of the variant /ami/ in the } \\
\text { schema les }+/ \mathrm{X} / \\
\text { Omission of the /z/ expected after } \\
\text { les: [leami] }\end{array}$ & $\begin{array}{l}\text { Decrease or stagnation } \\
\text { between } 2 \text { and } 6 \text { years } \\
\text { depending on the study } \\
\text { and social environment } \\
\text { (Chevrot et al., 2007, } \\
\text { 2011; Dugua, 2006). }\end{array}$ \\
\hline Correct liaison & $\begin{array}{l}\text { Insertion in a schema of a } \\
\text { C-initial variant starting with } \\
\text { a liaison compatible with the } \\
\text { determiner }\end{array}$ & $\begin{array}{l}\text { Insertion of the variant /zami/ in } \\
\text { the general schema les+/X/ or the } \\
\text { specific schema les }+/ \mathrm{zX} / \text {. } \\
\text { Correct production of the /z/ } \\
\text { expected after les: [lezami] }\end{array}$ & $\begin{array}{l}\text { Increase between } 2 \text { and } 6 \\
\text { years. Threshold of } 80 \% \\
\text { achieved at } 4 \text { - } 6 \text { years } \\
\text { (Chevrot et al., 2007, } \\
\text { 2011; Dugua, 2006). }\end{array}$ \\
\hline $\begin{array}{l}\text { Regularization } \\
\text { error }\end{array}$ & $\begin{array}{l}\text { Assimilation of the } / \mathrm{n} / \text { or } / \mathrm{z} / \\
\text { at the start of a noun by } \\
\text { means of a specific schema }\end{array}$ & $\begin{array}{l}\text { The noun nombril /nõbRil/ 'navel' } \\
\text { used after the determiner les is } \\
\text { assimilated via the schema } \\
\text { les+/zX/. } \\
\text { Production of /z/ instead of the } \\
\text { initial /n/ of nombril : [lezכ̃bRil] }\end{array}$ & $\begin{array}{l}\text { Peak of errors at } 4-5 \text { years } \\
\text { (age at which the level of } \\
\text { correct liaison reaches } \\
80 \% \text { ) and then decrease } \\
\text { (Chevrot et al., 2009). }\end{array}$ \\
\hline
\end{tabular}

Table 2 - Production mechanisms in the constructionist model (C/V-initial variant: consonant-initial or vowel-initial variant of the noun, e.g. /nami/ and /ami/). Development with age as identified in picture naming tasks, $\mathrm{N}>180$ (Chevrot et al., 2009, 2011; Dugua, 2006) and cross-sectional corpus studies (Chevrot et al., 2007).

By contrast, the regularization errors involve modifications to the segments. In these errors, children replace the initial segment of a consonant-initial noun (e.g. nombril /nכ̃bRil/ 'navel') with the liaison triggered by the preceding determiner. For example, they say [lezכ̃bril] ('the navels') instead of [lenכ̃bril] with the /z/ instead of the initial /n/ being precisely the liaison that the determiner les triggers. In this case, they create a variant of nombril starting with /z/ in order to satisfy the requirements of the les+/zX/ schema. These 
errors are indicators of the productivity of the specific schemas ${ }^{2}$. They suggest that, up to at least the age of 4-5 years, the /n/ of /nami/ (consonant-initial variant of the word ami 'friend') has a status similar to that of the initial /n/ of nombril 'navel' (consonant-initial word). It is for this reason that children create the variant /zכ̃bRil/ in contrast to /nכ̃bRil/, by analogy with the variant /zami/ in contrast to /nami/, or /zaRbR/ in contrast to /naRbR/, etc.

\subsection{Questions faced by the constructionist model}

The main reservation stated by Wauquier (2009) with regard to the constructionist scenario (which she terms the 'lexical scenario') is that it does not address the phonological dimension of liaison. Since it contains no definition of the notion of slot (represented by $\mathrm{X}$ in the schemas) at the syllabic and positional levels, Wauquier considers that this scenario fails to take account of the fact that liaisons can only appear in front of a vowel. According to the author (p.117), "[un+nX] implies that X starts with a vowel [...]. As currently formulated, this scenario predicts $[\ldots]$ that children can also produce the (liaison) before a consonant and say things like *[un+n-lavabo], *[des+z-lavabo] [i.e. /n/ or /z/ liaison before the consonantinitial noun lavabo 'washbasin']" (our translation, p.124). It is indeed true that no error of this type was observed among 389 children aged between 2 and 6 years who spoke aloud 7800 sequences consisting of a determiner or adjective followed by a consonant-initial noun (Chevrot et al., 2005). However, Wauquier's reservation is based on a misunderstanding. The symbols $/ \mathrm{nX} /$ or $/ \mathrm{zX} /$ in the notation used for the specific schemas do not refer to an $/ \mathrm{n} / \mathrm{or} / \mathrm{z} /$ liaison followed by a slot $\mathrm{X}$ that is able to accommodate a noun but instead to a word-variant starting with $/ \mathrm{n} /$ or $/ \mathrm{z} /$. More precisely, the schema lest/zX/ accounts for the following generalization: the determiner les is followed by a lexical variant which has a form starting in /z/. The second segment of French nouns starting with $/ \mathrm{n} /$ or $/ \mathrm{z} /$ is likely to be a vowel. As a result, if children insert a variant of the noun starting with /zV/ in a schema of type les+/zX/, they do not produce a liaison in front of a consonant.

During the second stage of the constructionist model, children are therefore able to produce correct liaisons other than by chance even though the liaison itself has undergone no change

\footnotetext{
${ }^{2}$ Another seemingly more direct interpretation consists of accepting that children have mis-segmented the noun nombril, positioning the word boundary after the /n/, and reuse the form /õbril/ after a determiner equipped with a final /z/ liaison. Unfortunately, Chevrot et al. (2009, experiments 4 and 5) have shown that children who make these errors know perfectly well that the nouns start with an $/ \mathrm{n} /$ or a /z/ and not with a vowel.
} 
in terms of lexical attachment or syllabic status. Instead, they have simply learnt that variants of the type $/ \mathrm{nX} /$ (e.g. /nami/, /narbR/, etc.) follow the determiner un whereas variants of the type /zX/ (e.g. /zami/, /zaRbR/) follow the determiners les or deux. This idea is reinforced by an experiment suggesting that these variants persist in the lexicon even when children have mastered liaison (Dugua et al., 2009). Some nouns which, for semantic reasons, are more frequently used in the plural (e.g. arbre 'tree', ongle 'fingernail') are more often preceded by a plural determiner that induces a liaison /z/ (les 'the+plural', des 'indefinite+plural', deux 'two', plusieurs 'many', etc). The type /zX/ variants of these nouns are therefore more frequent than the type $/ \mathrm{nX} /$ variants. Up to the age of 4 years, children produce more /z/ liaisons in combination with these nouns, either correctly (les arbres [lezaRbR]) or incorrectly (un arbre [气̃zaRbR]). The variants that are more frequent in the input are therefore more readily available. As of the age of 5-6 years, this frequency effect of number prevalence disappears in production but nevertheless persists at the level of perception. Plural-oriented nouns are recognized more quickly in the $/ \mathrm{zX} /$ form than in the $/ \mathrm{nX} /$ form (and vice-versa for singularoriented nouns). Consequently, the $/ \mathrm{nX} /$ or $/ \mathrm{zX} /$ variants of nouns induce a frequency effect during perceptual tasks even at an age when liaison errors have practically disappeared from children's productions.

Wauquier's second reservation (2009: 124) concerning the constructionist model relates to the absence of any unified modeling of liaisons. In effect, within this conception, liaisons are generated by means of schemas that are based on specific determiners (e.g. $\underline{u n+}+\mathrm{nX} /$, $\underline{\text { les }}+/ \mathrm{zX} /$ ). As a result, "children can only make generalizations on a context-by-context basis. This state of affairs predicts, for example, that the generalization they make in a context such as les éléphants (/lezelefã/ 'the elephants') will be of no [...] immediate use for the production of les gentils éléphants ('the nice elephants' (/lezãtizelefã/)" (our translation, p.124). The problem raised by Wauquier (2009) relates to the entire usage-based framework in which early morphosyntactic skills are structured around lexical items that form islands of organization (Tomasello, 2000). However, a transition to more general constructions remains possible due to the fact that all the item-based schemas are gradually organized to form a network (Tomasello, 2003) involving two types of relation: instance-category relations (e.g. item-based schemas les $+\mathrm{X}$ and nominal construction) and part-whole relations (nominal construction and clause construction). Chevrot et al. (2009) describe this type of development 
in the case of prenominal liaison. For instance, the establishment of relations between schemas involving a plural determiner and the /z/ liaison (deux+/zX/, trois $+/ z X /$, plusieurst/zX/, 'two', 'three', 'several') may result in a more abstract construction which associates the /z/ liaison with plural: [DETERMINER-z-[vowel]-NOUN] $]_{\text {plural }}$ according to the view proposed by Bybee (2001). Work is currently underway to establish the plausibility of this type of development beyond stage 2 of the constructionist model (Siccardi, in progress).

More generally, it is important to remember that, contrary to what Wauquier suggests (2009: 116), a construction is not a "formal structure [...] independent of the lexical contents it mobilizes" (our translation). In effect, one of the central postulates of the usage-based approach is that the formation of abstract constructions does not necessarily erase the concrete elements that underpin them (Kemmer \& Barlow, 2001; Abbot-Smith \& Tomasello, 2006). As a result, linguistic competence, as understood within the constructionist framework is organized in the form of strata which encode language information in a redundant way. As Dabrowska (2006) has shown with reference to the morphology of the dative of neuter nouns in Polish, linguistic knowledge of prenominal liaisons could be organized into strata of increasing levels of abstraction. The /z/ liaison present in les arbres 'the trees' would therefore be represented simultaneously as part of the memorized chunk /lezarbR/, as a segment with the lexical form /zarbR/, as an element in the local schema lest/zX/, and as a plural prefix of the noun.

Within this framework, it is important to know what levels are present at any given age. A reaction time experiment conducted among children aged 5-6 years goes some way to answering this question (Siccardi, in progress; Siccardi et al., 2011). On the one hand, it has duplicated the results obtained by Dugua et al. (2009): lexical access to adult vowel-initial words is faster when they are perceived in their most frequent variant (by comparing the $/ \mathrm{nX} /$ variants of singular-oriented words with the corresponding /zX/ variants). On the other, it shows that lexical access to nouns is sensitive to the frequency of the determiner-noun sequence (by comparing frequent sequences, e.g. un avion 'a plane', and infrequent sequences, e.g. ton avion 'your plane'). Since the frequency effect is an index of memorization, it is likely that children encode prenominal liaison at the level of variants of type /nX/ as well as at the level of frequent determiner-noun sequences.

A second question concerning the organization of linguistic knowledge in the form of strata of increasing levels of abstraction relates to the endpoint of this gradual process. Viewed from this angle, the phonological model proposed by Wauquier (2009) points to a 
specific characteristic of liaison that future developments of the constructionist model will have to take into account: the independence of syllabic and segmental information (see section 3.2, second stage). When the liaison is produced, the segment which expresses it is linked with the initial vowel of the following word to form a syllable whose onset then consists of the segment in question. Stage 2 of the constructionist model suggests that, in the case of variants of type $/ \mathrm{nX} /$ or $/ \mathrm{zX} /$ inserted in the specific schemas, the liaison inherently has the status of syllable onset. Nevertheless, this mechanism does not account for the possible relation between the linkage of liaisons and the linkage of fixed final consonants. Unlike liaisons, fixed final consonants are produced in all the various contexts (before a consonant, vowel or pause). Like liaisons, they are linked with the initial vowel of the following word to form a syllable. For example, the initial vowel of the noun abri 'shelter' leads to the linkage of the fixed final $/ /$ of the adjective fragile (fragile abri [frazilabRi] 'fragile shelter'), the /b/ of the adjective superbe (superbe abri [sypenbabRi] 'superb shelter'), the /d/ of the adjective solide (solide abri [solidabri] 'solid shelter'), etc. It is unlikely that children memorize as many variants of a noun as there are possible linkages of final consonants (e.g. /labRi/, /babRi/, /dabRi/, etc.), in particular given that some of the combinations are infrequent. The constructionist model must therefore examine the possible relations that children may establish between fixed final consonants and liaison consonants and, if appropriate, draw the relevant conclusions in terms of a phonological mechanism in which final consonantal segments are able to take on two syllabic positions.

\subsection{Questions faced by the phonological model}

Because the phonological model has been conceived of in terms of a progression toward the acquisition of double-floating autosegment status, it is able to account directly for the phenomenon of resyllabification. However, in our opinion, it suffers from other difficulties.

One initial question relates to stage 2, during which children are thought to use different means (statistical inference, default use of $/ \mathrm{j} /$, etc.) to assign segmental content to a nouninitial onset position. In this model, this variation between different strategies is thought to be responsible for liaison errors, whereas, in the constructionist model these errors have their source in the alternating selection of noun variants (see Table 2). 
The existence of such noun variants is compatible with three types of index: their presence at the start of an utterance ([nan] viens ici! 'Donkey, come here !' instead of [an], Chevrot et al., 2009, experiment 2), the relation between the singular/plural-orientation of the nouns and the prevalence of $/ \mathrm{z} /$ or /n/ (Dugua et al., 2009, experiment 1, see section 4.1), the tendency to segment determiner+pseudo-noun sequences by processing the $/ \mathrm{n} /$ or $/ \mathrm{z} /$ located at the word boundary as the initial consonant of the pseudo-noun (the sequence un-n-ivak [õnivak] is segmented un+nivak, Chevrot, et al., 2009, experiment 3). However, these results can also be interpreted as indicating the insertion of the segmental content at the start of the noun, as stage 2 of the phonological model assumes. In our opinion, only the primed error elicitation experiment conducted by Chevrot et al. (2009, experiment 1) rules out this interpretation. In this experiment, children aged 4-5 years had to produce a determiner-noun target sequence

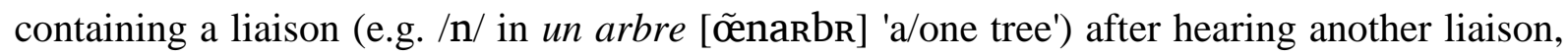
either before the same noun (e.g. /z/ in deux arbre [døzarbR] 'two trees') or before a different noun (e.g. /z/ in deux ours [døzurs] 'two bears'). The expected errors in the target ([0̃ezarbR] with /z/ instead of $/ \mathrm{n} /$ ) increased when the children heard the liaison followed by the same noun in the prime (e.g. [zarbR]) but not the liaison followed by another noun (e.g. [zuRs]). This pattern does not conform to the phonological model. If the children's errors simply resulted from filling an onset position with a phonetic content taken from the context, then simply hearing $[\mathrm{z}]$ in the prime [døzurs] should cause the error [õzarbR]. On the other hand, this pattern is compatible with the constructionist view. Hearing the variant [zaRbR] activates its representation and increases the likelihood of the error [ãzarbR] (see Gallot et al., 2009 for a similar experiment that primed the production of correct liaisons).

The second question facing the phonological model relates to the morphological bootstrapping that was cited as an explanation for the disappearance of errors during stage 3 . Children would encode a floating segment at the end of the determiner or adjective due to the similarity of the liaison and the consonant used in the inflected and derived forms. In the constructionist model, it is the memorization of determiner-noun sequences that include a liaison that results in the formation of schemas of type lest/zX/ which subsequently ensure correct production. The two models therefore lead to quite different predictions. In the case of 
the phonological model, children should produce correct liaisons following units having numerous and frequent inflected and derived forms. In the case of the constructionist model, initial progress should be achieved through familiarity with frequent word1-word2 collocations.

The very concept of bootstrapping implies that children "pull themselves up" on the basis of fundamental items of knowledge. Thus the fact that not all the determiners that are capable of forming liaisons possess inflected or derived forms does not constitute an argument against the morphological hypothesis. In fact, generalizations can be produced on the basis of just a few units. The bootstrapping hypothesis is attractive because it situates liaisons at the interface between phonology and morphology as of an early age. However, it still requires empirical support and this is lacking at present. Conversely, the constructionist hypothesis concerning sequence frequency has received some initial confirmation. Based on a case study conducted in a child aged 3-4 years, Chevrot et al. (2007) revealed a very strong correlation between the production of correct liaisons and the combinatory restrictions of 8 clitic pronouns or determiners accounting for at least 7 occurrences in the corpus. The combinatory restrictions of these units were estimated by the ratio between their number of occurrences in the corpus and the number of different word2s before which they appeared. This ratio peaked at 14.8 for the clitic pronoun en with 104 occurrences before 7 different word2s. The higher the ratio, the more frequently the word 1 s formed part of fixed word1-word 2 sequences. It was found that high levels of fixed sequences were associated with higher correct liaison rates. The pronoun en is the best placed on both scales since the /n/ liaison that follows it is correct in $97 \%$ of cases (the general level of correct categorical liaisons was $84 \%$ in this child). Furthermore, no significant correlation was observed between the accuracy level of liaison production and the frequency of either the word 1 or the word 2 in the corpus.

The third question confronting the phonological model relates to the mastery of variable liaisons during stage 4. This mastery is thought to be achieved at a late age (after 7-8 years) and to take the form, first, of the ability to distinguish between different contexts in which the double-floating autosegment mechanism is optional and then of discovering the social and stylistic value of the available options. Wauquier's (2009) formulation of stage 4 draws together a number of hypotheses which we shall consider separately.

Since variable liaisons act as a sociolinguistic variable, the production level in adults depends on both social status and style (for a review, see Nardy, 2008: 104-118). The mastery of such liaisons therefore has to be defined in terms of variations of usage. Furthermore, 
variable liaisons occur in many different contexts whose occurrence and associated level of production vary considerably in adults (Durand et al., 2011; Mallet, 2008). For all these reasons, it is difficult to consider this type of liaison to be a homogeneous phenomenon whose acquisition starts in the same way among all children once they have mastered the categorical liaisons. An actual comparison of the acquisition of the two types of liaison yields a rather more nuanced picture. Chevrot et al. (2011) asked 185 children aged 2-6 years to name pictures which required the production of either categorical liaisons, following the determiners un and deux, or variable liaisons, after the adjectives petit and gros. The children belonged to two groups with contrasted socioeconomic status (SES). The production of correct variable liaisons increased between 2 and 6 years. As of the age of 2-3 years, the accuracy scores for variable liaisons reached $15 \%$ and $20 \%$ for the lower and higher SES children, respectively. At 5-6 years, the difference between the two groups became significant, with scores of $21 \%$ and $41 \%$, respectively. During the same period, the percentage of correct categorical liaisons increased from 67\% to 97\% among the higher SES children and from $25 \%$ to $86 \%$ among the lower SES children. The phase during which the variable liaisons that occur after the prenominal adjective are acquired therefore overlaps with the acquisition of the categorical liaisons, even if we naturally assume that other types of variable liaison are acquired later. Furthermore, tests involving judgments of acceptability have shown that the ability to evaluate the normative dimension of variable liaisons emerges at the age of 5-6 years (Barbu et al., to appear). More generally, the position adopted by Wauquier (2009) in which the sociolinguistic aspects of liaisons are acquired later, is not consistent with the tendencies observed in a review of the works on sociolinguistic acquisition (Nardy et al., to appear). These tendencies suggest that the sociolinguistic aspects are inherent to the early acquisition process (as of 3-4 years) and do not follow on from an initial phase in which these aspects are absent.

\section{Generalizing liaisons in French as L1 and L2: longitudinal data}

The debate between the two models of liaison acquisition is not limited to the specific issues addressed in the two sections above. Wauquier (2009) correctly questions a general characteristic of the constructionist model which is as yet still largely undocumented. This relates to the form of the generalization process whose deployment is viewed as being gradual and piecemeal, in line with the usage-based framework. Conversely, as mentioned above, one feature of the phonological model lies in the sudden and irreversible nature of the generalization process: "children [...] appear to acquire liaison at a precise moment during 
their phonological development, which is interconnected with the acquisition of syntax and morphology, through grammatical generalization within categorical contexts and not on a context-by-context basis since once generalization has occurred at around the age of 4 years, the errors disappear." (Wauquier, 2009: 104, our translation). Seen from this point of view, the acquisition of liaisons among first language learners (L1) would be different from the acquisition observed in learners of French as a second language (L2) who, according to Wauquier (2009: 122), experience a lexical scenario similar to the constructionist model suggested by Chevrot et al. (2009) in the case of French-speaking children. Since they do not possess any phonological knowledge that makes it possible to clarify the surface opacity created by the liaison, learners would search, in the oral input, for the words that they have learned in writing and represent each categorical context in terms of a construction based on a lexical item.

This distinction between L1 and L2 is based on three claims (Wauquier, 2009: 109-110) : $1 /$ the acquisition trajectory of L1 children is more homogeneous than that of L2 learners; 2/ errors disappear definitively in L1 whereas they persist in L2; 3/ there are errors that are specific to L2 learners that testify to the influence of written forms (production of liaisons based on the phonographic value of the corresponding letter: grand ami 'great friend' produced with a liaison in $/ \mathrm{d} /$ rather than $/ \mathrm{t} /$ ). The third of these claims is supported by studies indicating the presence of phonographic errors in learners (Thomas, 2004, Harnois-Delpiano et al., 2012). A comparison of longitudinal studies conducted among French-speaking children (Dugua, 2006) and Korean learners of French (Delpiano-Harnois, 2006) will make it possible to examine the second claim concerning the stability of acquisitions. However, the data available at present do not permit us to test the first claim concerning the homogeneity of trajectories $^{3}$.

\subsection{Methodologies used in the two longitudinal studies}

Dugua (2006) traced the development of 20 native French-speaking children (10 girls and 10 boys) who were observed over a period of three years, while Harnois-Delpiano (2006) examined 16 Korean learners of French as a second language (4 men and 12 women) who

\footnotetext{
${ }^{3}$ It is possible to estimate the homogeneity of the L1 and L2 trajectories by comparing the standard deviation of correct and incorrect liaison scores. However, in order to perform this type of operation, it is necessary to match the two samples on performance level since the standard deviations fall systematically when the individual percentages approach $100 \%$ or $0 \%$. Our data do not permit this type of matching.
} 
were observed during a period of one-and-a-half years ${ }^{4}$. The ages of the subjects during these two studies are presented in Table 3 using the conventional notation (e.g. 2;5 means 2 years and 5 months).

\begin{tabular}{lccccc}
\hline & \multicolumn{2}{l}{ French-speaking children L1 $(\mathrm{N}=20)$} & \multicolumn{2}{l}{ Korean learners L2 (N=16) } \\
\cline { 2 - 6 } & Age range & Mean age & $\begin{array}{l}\text { Interval } \\
\text { between t and t-1 }\end{array}$ & Mean age & $\begin{array}{l}\text { Interval } \\
\text { between t and t-1 }\end{array}$ \\
\cline { 2 - 6 } Time 1 & $2 ; 5-3 ; 1$ & $2 ; 10$ & - & $20 ; 7$ & - \\
Time 2 & $3 ; 7-4 ; 3$ & $3 ; 11$ & $1 ; 1$ & $21 ; 1$ & $0 ; 6$ \\
Time 3 & $4 ; 2-4 ; 9$ & $4 ; 6$ & $0 ; 7$ & $21 ; 8$ & $0 ; 6$ \\
Time 4 & $4 ; 9-5 ; 5$ & $5 ; 2$ & $0 ; 8$ & $22 ; 2$ & $0 ; 6$ \\
Time 5 & $5 ; 6-6 ; 3$ & $5 ; 9$ & $0 ; 7$ & - & - \\
\hline
\end{tabular}

Table 3 - Age of the subjects in the longitudinal studies. Native French-speaking children (5 observation times); Korean adults learning French (4 observation times).

The French-speaking children attended nursery schools in a department in the South of France and were recorded on the school premises during individual sessions. The L2 learners of French consisted of 16 Korean students enrolled in the same year of the same French language and literature course at Mokwon University. They were recorded during individual passes between the end of their second year and half-way through their fourth year of studies. After being recorded, they completed a questionnaire which confirmed that they had only rare contact with French outside of the three hours of study they attended with a native teacher every week (for more details, see Delpiano-Harnois, 2006). These children and students took part in a number of experiments (see Delpiano-Harnois, 2006; Dugua, 2006) among which we shall present here a picture naming task requiring the production of liaisons between the determiner and the noun. For the French-speaking children, this task involved the production of eight noun phrases consisting of the determiners un (liaison $/ \mathrm{n} /$ ) and $\operatorname{deux}$ (liaison /z/) ('a/one', 'two') combined with the nouns arbre, ours, écureil, éléphant ('tree', 'bear', 'squirrel', 'elephant'). The children produced the phrases in a random order, with each target sequence alternating with a distracter sequence consisting of the same determiners and a consonantinitial liaison-impeding noun (balai, ballon, cochon, singe 'brush', 'ball', 'pig', 'monkey'). The protocol used for the students required the production of twelve phrases containing the

\footnotetext{
${ }^{4}$ Delpiano-Harnois (2006) and Harnois-Delpiano et al. (2012) presented only three observation times for their longitudinal studies. A fourth observation time has been transcribed and used for the present article.
} 
determiners un (liaison /n/) and trois (liaison /z/) ('a/one', 'three') combined with the nouns homme, arbre, ami, enfant, étudiant, appartement ('man', 'tree', 'friend', 'child', 'student', 'apartment'). The production of these target sequences alternated with the production of distracters formed from the same determiners in combination with liaison-impeding nouns (fleur, maison, restaurant, femme, bébé, professeur, ('flower', 'house', 'restaurant', 'woman', 'baby', 'teacher').

\subsection{Stability of liaison production in L1 and L2}

Table 4 lists the mean individual percentages of correct liaisons and errors ${ }^{5}$. A comparison of the start and end measurements in each longitudinal study reveals the following developments. In the French-speaking children, the percentage of correct liaisons increased significantly $\left(\mathrm{t}_{17}=-5.7, \mathrm{p}<.001\right)$, the number of substitution errors fell $\left(\mathrm{t}_{17}=5.9, \mathrm{p}<.001\right)$ whereas omissions can be considered to have remained stable $(p=.677)$. Among the students, correct productions increased $\left(\mathrm{t}_{15}=4.6, \mathrm{p}<.001\right)$, omissions fell $\left(\mathrm{t}_{15}=4.07, \mathrm{p}=.001\right)$ while substitution errors and spelling-like errors were stable (p>.27). In both cohorts, therefore, development consisted of gradually eliminating the errors that were prevalent during the initial periods of observation, i.e. substitutions in the L1 subjects and omissions in the L2 participants. The question is to determine whether the progress was more stable in one of these two cohorts.

\begin{tabular}{|c|c|c|c|c|c|c|c|}
\hline & \multicolumn{3}{|c|}{ French-speaking children L1 (N=20) } & \multicolumn{4}{|c|}{ Korean students L2 (N=16) } \\
\hline & $\begin{array}{l}\text { Correct } \\
\text { liaison }\end{array}$ & $\begin{array}{c}\text { Substitution } \\
\text { errors }\end{array}$ & $\begin{array}{l}\text { Omission } \\
\text { errors }\end{array}$ & $\begin{array}{l}\text { Correct } \\
\text { liaison }\end{array}$ & $\begin{array}{c}\text { Substitution } \\
\text { errors }\end{array}$ & $\begin{array}{l}\text { Omission } \\
\text { errors }\end{array}$ & $\begin{array}{c}\text { Spelling-like } \\
\text { errors }\end{array}$ \\
\hline Time 1 & $\begin{array}{l}45.7 \\
(25.9)\end{array}$ & $\begin{array}{c}37.3 \\
(25.3)\end{array}$ & $\begin{array}{c}17.0 \\
(30.5)\end{array}$ & $\begin{array}{l}51.3 \\
(32.6)\end{array}$ & $\begin{array}{c}3.2 \\
(7.5)\end{array}$ & $\begin{array}{c}44.9 \\
(32.0)\end{array}$ & $\begin{array}{c}1.0 \\
(4.2)\end{array}$ \\
\hline Time 2 & $\begin{array}{c}61.1 \\
(29.6)\end{array}$ & $\begin{array}{c}23.0 \\
(25.8)\end{array}$ & $\begin{array}{c}15.9 \\
(15.0)\end{array}$ & $\begin{array}{c}60.9 \\
(30.2)\end{array}$ & $\begin{array}{c}1.1 \\
(3.1)\end{array}$ & $\begin{array}{c}36.3 \\
(29.7)\end{array}$ & $\begin{array}{c}3.1 \\
(12.5)\end{array}$ \\
\hline Time 3 & $\begin{array}{c}77.4 \\
(24.7)\end{array}$ & $\begin{array}{c}10.0 \\
(16.1)\end{array}$ & $\begin{array}{c}13.6 \\
(16.2)\end{array}$ & $\begin{array}{c}69.5 \\
(28.4)\end{array}$ & $\begin{array}{c}1.7 \\
(3.6)\end{array}$ & $\begin{array}{c}28.8 \\
(27.5)\end{array}$ & $\begin{array}{c}0.0 \\
-\end{array}$ \\
\hline Time 4 & $\begin{array}{c}78.2 \\
(24.8)\end{array}$ & $\begin{array}{c}5.2 \\
(9.3)\end{array}$ & $\begin{array}{c}16.6 \\
(22.6)\end{array}$ & $\begin{array}{c}76.6 \\
(27.1)\end{array}$ & $\begin{array}{c}1.1 \\
(2.8)\end{array}$ & $\begin{array}{c}22.4 \\
(26.1)\end{array}$ & $\begin{array}{c}0.0 \\
-\end{array}$ \\
\hline Time 5 & $\begin{array}{c}84.2 \\
(22.0)\end{array}$ & $\begin{array}{c}1.1 \\
(2.8)\end{array}$ & $\begin{array}{c}14.7 \\
(21.1)\end{array}$ & & & & \\
\hline
\end{tabular}

Table 4 - Correct production and errors on determiner-noun liaisons during longitudinal studies: mean individual percentages and standard deviations

\footnotetext{
5 The percentage of correct liaisons was calculated using the following ratio: number of correct responses/(number of possible responses - (non-responses + liaison-inhibiting errors)). The liaison-inhibiting errors consisted, for example, of the suppression of the first syllable of the noun. The same formula was used to calculate the percentages of errors.
} 
An acquisition can be considered to be stable if the production of a correct form up to a time $t$ is not followed by errors at time $t+n$. For each subject, we considered the number of residual errors arising in a specific determiner-noun sequence after a correct liaison had been produced in this sequence. For example, if a subject $\mathrm{S}$ successively produced a substitution, a correct /n/ liaison, a substitution, and two correct /n/ liaisons for the sequence un ours at the five observation times during the longitudinal study then the number of residual errors was 1 because only the substitution at time 3 occurred after the first correct production at time 2 . By calculating this value as a proportion of the total number of errors observed for each child, we were thus able to obtain the individual proportion of residual errors. If this proportion was small then the resolution of the errors was "definitive and irreversible" (Wauquier, 2009: 110, our translation). If it was high then the errors tended to persist after the first correct production. The means of these proportions are presented in Table 5 which distinguishes between different types of error for each cohort of subjects.

\begin{tabular}{ccccccc}
\hline French-speaking children L1 $(\mathrm{N}=20)$ & & \multicolumn{2}{c}{ Korean students L2 (N=16) } \\
\hline & $\begin{array}{c}\text { All errors } \\
\text { combined }\end{array}$ & $\begin{array}{c}\text { Omission } \\
\text { errors }\end{array}$ & $\begin{array}{c}\text { Substitutions } \\
\text { errors }\end{array}$ & $\begin{array}{c}\text { All errors } \\
\text { combined }\end{array}$ & $\begin{array}{c}\text { Omission } \\
\text { errors }\end{array}$ & $\begin{array}{c}\text { Substitutions and } \\
\text { spelling-like } \\
\text { errors }\end{array}$ \\
Longitudinal obs. & 30.0 & 23.6 & 6.6 & & & 2.3 \\
times 1-5 & $(21.6)$ & $(23.7)$ & $(9.3)$ & 11.7 & 9.4 & $(5.1)$ \\
Longitudinal obs. & 26.4 & 18.8 & 6.2 & $(12.6)$ & $(9.6)$ & \\
times 1-4 & $(25.4)$ & $(23.7)$ & $(7.9)$ & & & \\
\hline
\end{tabular}

Table 5 - Proportions of residual errors occurring after the first correct production of each determiner-noun sequence (mean individual percentages and standard deviations).

The proportion of residual errors was calculated in two ways for the French-speaking children: on the one hand, across all five observation times during the longitudinal study and, on the other, over the first four observation times in order to align the data with that for the student learners of French who were only observed four times. When all types of errors are considered together, residual errors were more frequent in the L1 children $(30.0 \%$ and $26.4 \%)$ than among the L2 learners $(11.7 \%)$. The difference is significant whether we consider the proportions of residual errors for $\mathrm{L} 1$ across the five observation times $\left(\mathrm{t}_{32}=3.18, \mathrm{p}=.003\right)$ or four observation times in the longitudinal study $\left(\mathrm{t}_{32}=2.0, \mathrm{p}=.05\right)$. If we restrict the calculation to omission errors, the proportion of errors was still greater in L1 (23.6\% and 18.8\%) than L2 (9.4\%). This difference is significant if we consider the five observation times for the L1 children $\left(\mathrm{t}_{32}=2,1 ; \mathrm{p}=.04\right)$ but not when only four observation times are considered $(\mathrm{p}=.12)$. 
Finally, residual substitution errors were more frequent in L1 $(6.6 \%$ and $6.2 \%)$ than in L2 $(2.3 \%)$. The difference is marginally significant whether we consider all five observation times for the $\mathrm{L} 1$ children in the longitudinal study $\left(\mathrm{t}_{32}=1,727, \mathrm{p}<.10\right)$ or only four times $\left(\mathrm{t}_{32}=1,714, \mathrm{p}<0.10\right)$.

More than a quarter of the errors produced by the French-speaking children occurred after the production of a correct liaison, whereas this proportion was less than $12 \%$ among the student learners. This result is not compatible with the idea that generalization is more systematic among French-speaking children as the phonological model predicts. Instead, it is consistent with the constructionist model. In children, general schemas of the type $u n+/ \mathrm{X} /$ remain active after the formation of specific schemas of the type $u n+/ \mathrm{nX} /$ during stage 2 . Indeed, these schemas must remain active because they cover the majority of noun phrases which have no liaison and include nouns starting with a consonant. General schemas and specific schemas are therefore in competition with one another during the production of phrases containing a liaison. When the general schema wins, this competition leads to the errors that are typical of stage 1. Conversely, in learners of French as a second language, the acquisition of liaison seems to be more stable. This stability is consistent with the idea that L2 phonology would be partly influenced by the written form (Detey \& Nespoulous, 2008), which is a stable cue.

\section{Conclusion}

The debate between the two models of liaison acquisition reveals uncertainties on both sides which will have to be investigated in future research.

The task of the constructionist model (Chevrot et al., 2009) is now to specify in detail the later stages in the acquisition of prenominal liaisons and consider the emergence of a more abstract level of representation than the formation of schemas constructed on the basis of specific words. The possibility that the prenominal liaison might function as a noun prefix (Morin \& Kaye, 1982) and the relation between liaison and linkage outside of liaison contexts must be examined. Whatever the results may be, these new developments will help test a central postulate of the usage-based theories: the redundant encoding of linguistic information in strata of increasing levels of abstraction. Orthographic information may also have a place in this type of representation (Chevrot \& Malderez, 1999; Laks, 2005).

As far as the phonological model is concerned, it is necessary to document the hypothesis that liaison errors result from the filling of an onset position located at the start of a noun using a segmental content selected by default, inferred from the context or deduced on the 
basis of a probabilistic calculation. To defend their position, the advocates of the phonological model point to the example of errors in which the liaisons are replaced by segments which cannot be liaisons (les oiseaux 'the birds' pronounced [lejajo] with [j] instead of the expected /z/ liaison, Wauquier, 2009:105). However, this argument can be countered with the observation that this type of error is extremely rare: $97.8 \%$ of the liaison errors in children aged 2 to 6 take the form of the intrusion of /n/, /z/, /t/ and /l/ (Chevrot et al., 2009). Similarly, the hypothesis that progress in the acquisition of liaisons results from morphological bootstrapping based on inflected or derived forms must be contrasted with an alternative for which some empirical support is starting to emerge: the early mastery of liaisons in frequent determiner-noun collocations. Finally, the phonological model must explain in greater depth the strict distinction that it makes between categorical liaisons, whose early mastery is said to result from phonological generalization, and variable liaisons which are considered to be the object of late pragmatic learning. In certain contexts, the periods of acquisition of the two types of liaison overlap. Furthermore, both types give rise to correct productions and errors at the age of 2-3 years (Chevrot et al., 2011).

Whichever model we consider, the debate cannot be continued without a better understanding of the linguistic material on the basis of which children memorize and generalize. In other words, it is becoming necessary to describe the use of liaisons in parentchild interactions and establish a relation between the quality and frequency of the input and the progress made by children. Concerning this point, Liégeois et al. (2011) have contributed preliminary results based on a more extensive study. These results come from a longitudinal observation of two small girls recorded with their parents at an interval of 8 months (at 28 and 36 months in one case and 40 and 48 months in the other). It can be seen that the word1word2 sequences containing categorical liaisons are more fixed in child-directed speech than they are in exchanges between adults. Moreover, this level of rigidity is greater the younger the children are. These initial results argue in favor of the central role that the constructionist model assigns to word1-word2 sequences in the acquisition of liaisons.

We welcome the way in which Wauquier (2009) has extended the scope of the debates reported in this article. The functioning and acquisition of liaisons provides us with information about the possibility of conceiving of a phonological component that is independent of the lexicon or, in other words, of accounting for alternation by means of a general phonological mechanism rather than on the basis of a competition involving 
constructions and lexical variants. Converging experiments conducted in adults suggest that certain phenomena that are considered to be segmental alternations - the internal schwa in French and the nasal flap in English - are in fact underpinned by processes involving competition between lexical variants (Connine \& Pinnow, 2006; Bürki et al., 2010, 2011; Racine \& Grosjean, 2005; Ranbom \& Connine, 2007). However, unlike the internal schwa and the nasal flap, liaisons occur at word boundaries. This characteristic has two consequences. On the one hand, it implies linkage phenomena between words which raise the crucial question of syllabic structure. On the other, it mobilizes the interface between lexicon and syntax. By according a central, structuring role to the memorization of word sequences, the constructionist conception forms part of what Bybee \& McClelland (2005) have termed the alternative to the combinatorial paradigm. The study of liaisons therefore also raises questions concerning the possibility of conceiving of a syntactic component that is independent of the lexicon. Finally, the acquisition of variable liaisons, i.e. a sociolinguistic trait that has been thoroughly described in French, represents a promising field for examining the formation of the link between social and linguistic knowledge.

The debates surrounding these issues that we have reported here are likely to flourish in the future since they document general assumptions relating to the very nature of linguistic knowledge. Nevertheless, the advocates of the various theoretical options must avoid the pitfall that characterizes certain approaches to liaisons in adults: the construction of sets of arguments derived from a closed and limited empirical base (Laks, 2011). Thus, the reach and value of future debates will depend on the richness and precision of the data supporting the two models.

\section{References}

Abbot-Smith, K., Tomasello, M., 2006. Exemplar-learning and schematization in a usagebased account of syntactic acquisition. The Linguistic Review 23, 275-290.

Arnon, I., Snider, N., 2010. More than words: frequency effects for multi-word phrases. Journal of Memory and Language 62 (1), 67-82.

Bannard, C., Matthews, D., 2008. Stored word sequences in language learning: the effect of familiarity on children's repetition of four-word combinations. Psychological Science 19 (3), 241-248.

Barbu, S., Nardy, A., Chevrot, J.-P., Juhel, J., to appear. Language evaluation and use during early childhood: Social norms or environmental regularities? Linguistics.

Boë, L.-J., Tubach, J.-P., 1992. "De A à Zut": dictionnaire phonétique du français parlé. Ellug, Grenoble.

Bürki, A., Alario, F.-X., Frauenfelder, U. H., 2011. Lexical representation of phonological variants: Evidence from pseudohomophone effects in different regiolects. Journal of Memory and Language 64, 424-442. 
Bürki, A., Ernestus, M., Frauenfelder, U. H., 2010. Is there only one "fenêtre" in the production lexicon? On-line evidence on the nature of phonological representations of pronunciation variants for French schwa words. Journal of Memory and Language 62, 421437.

Bybee, J. L., 2001. Frequency effects on French liaison. In: Bybee, J.L., Hopper, P. (Eds.), Frequency and the emergence of linguistic structure. John Benjamins, Philadelphia, pp. 337359.

Bybee, J. L., McClelland, J., 2005. Alternatives to the combinatorial paradigm of linguistic theory based on domain general principles of human cognition. The Linguistic Review 22 (24), 381-410.

Chabanal, D., 2003. Un aspect de l'acquisition du français oral: la variation socio-phonétique chez l'enfant francophone. Thèse de doctorat, Université Paul Valéry, Montpellier.

Chevrot, J.-P., Malderez, I., 1999. L'effet Buben: de la linguistique diachronique à l'approche cognitive (et retour). Langue Française 124, 104-125.

Chevrot, J.-P., Chabanal, D., Dugua, C., 2007. Pour un modèle de l'acquisition des liaisons basé sur l'usage: trois études de cas. Journal of French Language Studies 17 (1), 103-128.

Chevrot, J.-P., Dugua, C., Fayol, M., 2005. Liaison et formation des mots en français: un scénario développemental. Langages 158, 38-52.

Chevrot, J.-P., Dugua, C., Fayol, M., 2009. Liaison acquisition, word segmentation and construction in French: a usage based account. Journal of Child Language 36 (3), 557-596.

Chevrot, J.-P., Nardy, A., Barbu, S., 2011. Developmental dynamics of SES-related differences in children's production of obligatory and variable phonological alternations. Language Sciences 33 (1), 180-191.

Clements, G.N., Keyser S.J., 1983. CV phonology: A Generative Theory of the Syllable. MIT Press, Cambridge.

Connine, C. M., Pinnow, E., 2006. Phonological variation in spoken word recognition: Episodes and abstraction. The Linguistic review 23, 235-245.

Côté, M.-H., 2011. French liaison. In: van Oostendorp, M., Ewen, C., Hume, E., Rice, K. (Eds), Companion to phonology. Wiley-Blackwell, Malden, MA, pp. 2685-2710.

Croft, W., Cruse, D. A., 2004. Cognitive Linguistics. Cambridge University Press, Cambridge.

Dabrowska, E., 2004. Rules or schemas? Evidence from Polish. Language and Cognitive Processes 19, 225-271.

Delpiano-Harnois, M., 2006. Etude longitudinale de l'acquisition des liaisons chez l'apprenant coréen de Français Langue Etrangère : comparaison avec un modèle développemental attesté chez des enfants francophones natifs. Diplôme Supérieur de Recherche, Université Stendhal.

Detey, S. \& Nespoulous, J.-L. (2008). Can orthography influence second language syllabic segmentation? Japanese epenthetic vowels and French consonantal clusters. Lingua 118, 6681 .

Dugua, C., 2006. Liaison, segmentation lexicale et schémas syntaxiques entre 2 et 6 ans: un modèle développemental basé sur l'usage. Thèse de doctorat, Université Stendhal, Grenoble.

Dugua, C., Spinelli, E., Chevrot, J.-P., Fayol, M., 2009. Usage-based account of the acquisition of liaison: evidence from sensitivity to the singular/plural orientation of nouns. Journal of Experimental Child Psychology 102 (3), 342-350.

Durand, J., Laks, B., Calderone, B., Tchobanov, A., 2011. Que savons-nous de la liaison aujourd' hui ? Langue Française 169, 103-135.

Durand, J., Lyche, C., 2008. French liaison in the light of corpus data. Journal of French Language Studies 18 (1), 33-66.

Encrevé, P., 1988. La liaison avec et sans enchaînement. Édition du Seuil, Paris. 
Gallot, S., Spinelli, E., Chevrot, J.-P., Dugua, C., 2009. Le rattachement lexical de la liaison: une expérience d'amorçage chez des enfants pré-lecteurs. Psychologie Française 54, 355-361. Goldberg, A. E., 2003. Constructions: a new theoretical approach to language. Trends in Cognitive Sciences 7 (5), 219-224.

Goyet, L., de Schonen, S., Nazzi, T., 2010. Words and syllables in fluent speech segmentation by French-learning infants: an ERP study. Brain Research 1332, 75-89.

Harnois-Delpiano, M., Cavalla, C., Chevrot, J.-P., 2012. L'acquisition de la liaison en L2: étude longitudinale chez des apprenants coréens de FLE et comparaison avec des enfants francophones natifs. In : Neveu, F., Muni Toke, V., Blumenthal, P., Klingler, T., Ligas, P., Prévost, S., Teston-Bonnard, S. (Eds.). Actes du 3ème Congrès Mondial de Linguistique Française, Lyon, France, 4-7 Juillet 2012, pp. 1575-1589.

Janssen, N., Barber, H.A., 2012. Phrase Frequency Effects in Language Production. PLoS ONE 7 (3), e33202. doi:10.1371/journal.pone.0033202

Kemmer, S., Barlow, M., 2000. Introduction: a usage-based conception of language. In: Barlow, M., Kemmer, S. (Eds.), Usage-based models of language. CSLI Publications Stanford, pp. vii-xxviii.

Laks, B., 2005. La liaison et l'illusion. Langages 158, 101-125.

Laks, B. (2011). La phonologie du français et les corpus, Langue Française, 169, 3-17.

Liégeois, L., Chabanal, D., Chanier, T., 2011. La liaison en discours adressé à l'enfant, spécificités et impacts sur l'acquisition. Colloque du Réseau Français de Phonologie, 1-3 Juillet 2011, Tours.

Mallet, G., 2008. La liaison en français: descriptions et analyses dans le corpus PFC. Thèse de doctorat, Université Paris X, Nanterre, Paris.

Mattys, S. L., Jusczyk, P. W., 2001. Do infants segment words or recurring continuous patterns? Journal of Experimental Psychology: Human Perception and Performance 27 (3), 644-655.

Morin, Y.-C., Kaye, J., 1982. The syntactic bases for liaison. Journal of Linguistics 18 (2), 291-330.

Nardy, A., 2008. Acquisition des variables sociolinguistiques entre 2 et 6 ans: facteurs sociologiques et influences des interactions au sein du réseau social. Thèse de doctorat, Université Stendhal, Grenoble.

Nardy, A., Chevrot, J.-P., Barbu, S., to appear. The acquisition of sociolinguistic variation: looking back and thinking ahead. Linguistics.

Nicoladis, E., Paradis, J., 2011. Learning to liaise and elide comme il faut: evidence from bilingual children. Journal of Child Language 38 (4), 701-730.

Peters, A., 1985. Language segmentation: operating principles for the perception and analysis of language. In: Slobin, D. (Ed.), The Crosslinguistic Study of Language Acquisition. Erlbaum, Hillsdale, pp. 1029-1067.

Pine, J. M., Lieven, E., 1993. Reanalysing rote-learned phrases: individual differences in the transition to multi word speech. Journal of Child Language 20 (3), 551-571.

Pine, J. M., Lieven, E., 1997. Slot and frame patterns in the development of the determiner category. Applied Psycholinguistics 18 (2), 123-138.

Racine, I., Grosjean, F., 2005. Le coût de l'effacement du schwa lors de la reconnaissance des mots en français. Canadian Journal of Experimental Psychology 59 (4), 240-254.

Ranbom, L. J., Connine, C. M., 2007. Lexical representation of phonological variation in spoken word recognition. Journal of Memory and Language 57, 273-298.

Siccardi, A., Chevrot, J.-P., Spinelli, E., 2011. The storage of multiword sequences in children and adults: what we can learn from the acquisition of French liaison. International Child Phonology Conference, York, 16-17 June 2011. 
Siccardi, A., in progress. Séquences et unités dans le lexique adulte et enfantin : le cas de la liaison. Thèse de doctorat, Université Stendhal, Grenoble.

Thomas, A., 2004. Phonetic norm versus usage in advanced French as a second language. International Review of Applied Linguistics 42, 365-382.

Tomasello, M., 2000. Do young children have adult syntactic competence? Cognition 74, 209-253.

Tomasello, M., 2003. Constructing a language: a usage-based theory of language acquisition. Harvard University Press, Cambridge and London.

Wauquier, S., 2009. Acquisition de la liaison en L1 et L2 : stratégies phonologiques ou lexicales? Aile...Lia 2, 93-130.

Wauquier-Gravelines, S., Braud, V., 2005. Proto-déterminant et acquisition de la liaison obligatoire en français. Langages 158, 53-65.

Wauquier-Gravelines, S., Encrevé, P., Scheer T., 2005. Liaison in French, towards an unified explanation of variation. Colloque Phonologie du Français Contemporain, Phonological Variation, the case of French, Troms $\varnothing$, Norway, 25-27 august 2005. 